\title{
An EOQ Model for Weibull Deteriorating Items With Price Dependent Demand
}

\author{
Sushil Kumar* \& U.S.Rajput \\ Department of Mathematics \& Astronomy, University of Lucknow, Lucknow -226007. U.P. India
}

\begin{abstract}
In the present paper we developed an economic order quantity model for Weibull deteriorating items with price dependent demand rate together with a replenishment policy for profit maximization. The demand rate is a continuous and differentiable function of price. The variable items deteriorate with time shortages are allowed and completely back-ordered. Further it is illustrated with the help of numerical examples.
\end{abstract}

Keywords: Weibull distribution, Price-dependent demand rate and Varying rate of deterioration.

\section{Introduction}

An optimal replenishment policy is dependent on ordering cost, set-up cost and shortage cot. Many mathematical models have been developed for controlling inventory and in the earlier models many researchers consider constant demand rate, while in most of the cases demand of the items increases with time but most of the organizations are working for increasing demand of their items with time. Basically the items which are stored for future use always loose part of their value with time and this phenomenon is known as deterioration of items. The rate of deterioration is very small in some items like hardware, glassware, steel and the items such as medicine, vegetables, gasoline, alcohol, radioactive chemicals and food grains deteriorate rapidly over time so the effect of deterioration of physical goods cannot be disregarded in many inventory systems. Controlling and regulating of deteriorating items is a major problem in any inventory system. In deterministic inventory models constant demand rate is assumed. Covert and Philip [1] considered the constant demand rate for deteriorating items by using a two parameter Weibull distribution, further this model was generalized by Philip [2] by assuming three parameter Weibull distribution. Mishra [3] developed an inventory model with finite rate of replenishment by assuming a two parameter Weibull distribution. Several researchers like Shah and Jaiswal [4], Aggarwal [5] modified the Roy and Chaudhary [6] model by considering different type of deterioration and replenishment rate. Empirically it has been observed that the failure and life expectancy of many items can be expressed in terms of Weibull distribution. Covert and Philip [1] extended Ghare and Schrader [7] model by considering an EOQ model with a variable rate of two parameter Weibull distribution. Several researchers like Tadikamalla [8], Mukhopadhyay et al [9, 10], Chakrabarty et al [11] developed an economic order quantity model.

The realistic models treat with a time varying deterioration rate. In a lot of theoretical papers deterioration rate is followed by Weibull distribution. Goyal and Giri [12] gave the main attention towards this topic. Several researchers like Chakrabarty et al [11], Chen and Lin [13], Ghosh and Chaudhury [14], Mahapatra and Maiti [15], Mondal et al [16], Wu and Lee [17] gave many results with the units of product in stock that are deteriorated. Most of the researchers assumed constant rate of deterioration in their models. Weibull distribution is used for the products in stock that are deteriorated with time. Wagner and Whitin [18] considered an inventory model for products which deteriorate at the end of a prescribed storage period. Ghare and Schrader [7] modified an EOQ model by assuming an exponential decay in inventory. Further this model was extended by Shah [19], Goyal and Aggarwal [20] by assuming varying rate of deterioration by a three parameter Weibull distribution.

In real life situations the retailers lot size is affected by the demand of the product and the demand is dependent on the price of the product so the problems of determining the retail price and lot size are inter dependent. Kim et al [21] studied both price and lot size problems for deteriorating products with constant rate of deterioration Wee [22] studied the joint pricing abd replenishment policy for deteriorating inventory with decline demand rate over time.. Abad [23] studied the problem of both lot sizing and dynamic pricing of perishable product under partial back-logging of demand. In the competitive market the effect of price variation of a product changes its selling rate, lesser selling price increases the selling rate and higher selling price decreases the selling rate. Hence the selling rate of an item is a function of selling price. Several researchers like Ladnay and Sternleib [24], Goyal and Gunasekaran [25], Luo [26], Weng [27], Subramanyam and Kumaraswamy [28] and Daset al [29] developed their models with price variations for deteriorating items. R. Begum, R.R Sahoo, S.K. Sahu and M. Mishra [30] developed an EOQ model for three parameter Weibull deteriorating items with price dependent demand rate. In the present paper we developed an instantaneous 
replenishment policy for two parameter Weibull deteriorating items with price dependent demand rate under profit maximization, shortages are allowed and completely back-ordered.

\section{Assumptions and Notation}

We consider the following assumptions and notations

1. The demand rate $\mathrm{d}(\mathrm{s})=\mathrm{a}-\mathrm{bs}$, where $\mathrm{a}, \mathrm{b}>0$, and $\mathrm{s}$ is the selling price.

2. Replenishments are instantaneous with negligible lead time.

3. The deterioration rate $\theta(t)=\alpha \beta t^{\beta-1}$

4. The replenishment quantity and cycle length are constant for each cycle.

5. Units are available for satisfying demand after replenishment.

6. $\mathrm{c}$ is the deteriorated cost of each unit.

7. $C_{1}, C_{2}, C_{3}$ are the fixed production cost per cycle, inventory carrying cost, shortage cost per unit backordered per unit time.

8. $\mathrm{T}$ is the cycle length, $T_{1}$ is the time for deterioration in the inventory cycle, $\left(T-T_{1}=T_{2}\right)$ is the time in the inventory when stock-out occur.

9. $\mathrm{I}(\mathrm{t})$ is the time varying inventory level in the inventory cycle.

10. During stock-out period demand is completely satisfied by the next replenishment.

11. $\mathrm{S}$ is the maximum inventory level at time $\mathrm{t}=0$ in the inventory cycle.

\section{Mathematical Formulation}

The instantaneous inventory level of the system at any time is given by the differential equations

$$
\frac{d I}{d t}+\alpha \beta t^{\beta-1}=-(a-b s), 0 \leq t \leq T_{1}
$$

With boundary conditions

$$
\begin{aligned}
& I(0)=S, \\
& \frac{d I}{d t}=-(a-b s), \quad T_{1} \leq t \leq T_{2},
\end{aligned}
$$

With boundary conditions

$$
I\left(T_{1}\right)=0
$$

The solution of the equations (1) and (2) are given by

$$
\begin{aligned}
& I=-d(s)\left[t-\frac{\alpha \beta T^{\beta+1}}{(\beta+1)}-\frac{\alpha^{2} t^{2 \beta+1}}{(\beta+1)}\right]-\frac{S}{d(s)}\left[1-\alpha t^{\beta}\right], \ldots \ldots \ldots . . .(3) \\
& I=d(s)\left[T_{1}-t\right] \\
& 0 \leq t \leq T_{1}
\end{aligned}
$$

$$
T_{1} \leq t \leq T_{2}
$$

Due to the deterioration loss of stock is

$$
\begin{gathered}
D\left(T_{1}\right)=I_{\text {max }}-d(s) T_{1} \\
D\left(T_{1}\right)=S-d(s) T_{1}
\end{gathered}
$$

Therefore average deterioration cost in $\left[0, T_{1}\right]$ is $=\frac{1}{T} \int_{0}^{T_{1}} c D\left(T_{1}\right) d t$

$$
=\frac{c}{T}\left[S T_{1}-\frac{d(s) T_{1}^{2}}{2}\right],
$$

Average production cost is $=\frac{C_{1}}{T}$ 


$$
\begin{aligned}
& \text { Average holding cost is }=\frac{1}{T} \int_{0}^{T_{1}} I(t) d t \\
& =-\frac{d(s)}{T}\left[\frac{T_{1}^{2}}{2}-\frac{\alpha \beta T_{1}^{\beta+2}}{(\beta+1)(\beta+2)}-\frac{\alpha^{2} T_{1}^{2(\beta+1)}}{2(\beta+1)^{2}}\right]-\frac{S}{T d(s)}\left[T_{1}-\frac{\alpha T_{1}^{\beta+1}}{(\beta+1)}\right]
\end{aligned}
$$

Average back-order cost is $=\frac{1}{T} \int_{T_{1}}^{T} I(t) d t$

$$
=\frac{d(s)}{T}\left[2 T T_{1}-2 T_{1}^{2}-\frac{T^{2}}{2}\right],
$$

Therefore total average cost is

$$
\begin{gathered}
T C\left(T, s, T_{1}\right)=\frac{c}{T}\left[S T_{1}-\frac{d(s) T_{1}^{2}}{2}\right]+\frac{C_{1}}{T}-\frac{C_{2} d(s)}{T}\left[\frac{T_{1}^{2}}{2}-\frac{\alpha \beta T_{1}^{\beta+2}}{(\beta+1)(\beta+2)}-\frac{\alpha^{2} T_{1}^{2(\beta+1)}}{2(\beta+1)^{2}}\right] \\
-\frac{C_{2} S}{T d(s)}\left[T_{1}-\frac{\alpha T_{1}^{\beta+1}}{(\beta+1)}\right]+\frac{C_{3} d(s)}{T}\left[2 T T_{1}-2 T_{1}^{2}-\frac{T^{2}}{2}\right]
\end{gathered}
$$

When there is no shortage in $\left[0, T_{1}\right]$ then $T_{1}=T$ and d(s) $=\mathrm{d}$, using in (9) so

$$
\begin{aligned}
T C(T, s)= & \frac{c}{T}\left[S T-\frac{d T^{2}}{2}\right]+\frac{C_{1}}{T}-\frac{C_{2} d}{T}\left[\frac{T^{2}}{2}-\frac{\alpha \beta T^{\beta+2}}{(\beta+1)(\beta+2)}-\frac{\alpha^{2} T^{2(\beta+1)}}{2(\beta+1)^{2}}\right] \\
& -\frac{C_{2} S}{T d}\left[T-\frac{\alpha T^{\beta+1}}{(\beta+1)}\right]+\frac{C_{3} d}{T}\left[2 T^{2}-2 T^{2}-\frac{T^{2}}{2}\right] \\
T C(T, s)= & C\left[S-\frac{d T}{2}\right]+\frac{C_{1}}{T}-C_{2} d\left[T-\frac{\alpha \beta T^{\beta+1}}{(\beta+1)(\beta+2)}-\frac{\alpha^{2} T^{2 \beta+1}}{2(\beta+1)^{2}}\right] \\
& -\frac{C_{2} S}{d}\left[1-\frac{\alpha T^{\beta}}{(\beta+1)}\right]-\frac{C_{3} d T}{2} \quad \ldots \ldots \ldots . . .(10)
\end{aligned}
$$

Therefore,

Net Profit $=$ Revenue - Average Cost

$$
\begin{aligned}
N P(s, T)= & (s-c) d-\left[c\left(S-\frac{d T}{2}\right)+\frac{C_{1}}{T}-C_{2} d\left\{T-\frac{\alpha \beta T^{\beta+1}}{(\beta+1)(\beta+2)}-\frac{\alpha^{2} T^{2 \beta+1}}{2(\beta+1)^{2}}\right\}\right. \\
& \left.-\frac{C_{2} S}{d}\left\{1-\frac{\alpha T^{\beta}}{(\beta+1)}\right\}-\frac{C_{3} d T}{2}\right] \quad \ldots \ldots \ldots(11)
\end{aligned}
$$

For maximization of net profit NP [s, T], 


$$
\begin{aligned}
\frac{\partial N}{\partial T}= & {\left[\frac{c d}{2}+\frac{C_{1}}{T^{2}}+C_{2} d\left\{1-\frac{\alpha \beta T^{\beta}}{(\beta+2)}-\frac{\alpha^{2}(2 \beta+1) T^{2 \beta}}{2(\beta+1)^{2}}\right\}-\frac{\alpha \beta C_{2} S T^{\beta-1}}{(\beta+1) d}+\frac{C_{3} d}{2}\right] } \\
\frac{\partial N}{\partial s}= & d(s)+(s-c) d^{\prime}+\left[\frac{c d^{\prime} T}{2}+C_{2} d^{\prime}\left\{T-\frac{\alpha \beta T^{\beta+1}}{(\beta+1)(\beta+2)}-\frac{\alpha^{2} T^{2 \beta+1}}{2(\beta+1)^{2}}\right\}\right. \\
& \left.-\frac{C_{2} S d^{\prime}}{d^{2}}\left\{1-\frac{\alpha T^{\beta}}{(\beta+1)}\right\}+\frac{C_{3} d^{\prime} T}{2}\right]
\end{aligned}
$$

Since $\frac{\partial N}{\partial T}=0$ and $\frac{\partial N}{\partial s}=0$, gives the optimum values of $\mathrm{T}=\mathrm{T}^{*}$ and $\mathrm{s}=\mathrm{s}^{*}$

$$
\frac{\partial^{2} N}{\partial T^{2}}=\left[-\frac{2 C_{1}}{T^{3}}+C_{2} d\left\{-\frac{\alpha \beta^{2} T^{\beta-1}}{(\beta+2)}-\frac{\alpha^{2} \beta(2 \beta+1) T^{2 \beta-1}}{(\beta+1)^{2}}\right\}-\frac{\alpha \beta(\beta-1) S C_{2} T^{\beta-2}}{(\beta+1) d}\right]
$$

$$
\begin{aligned}
\frac{\partial^{2} N}{\partial s^{2}}= & 2 d^{\prime}+(s-c) d^{\prime \prime}+\left[\frac{c T d^{\prime \prime}}{2}+C_{2} d^{\prime \prime}\left\{T-\frac{\alpha \beta T^{\beta+1}}{(\beta+1)(\beta+2)}-\frac{\alpha^{2} T^{2 \beta+1}}{2(\beta+1)^{2}}\right\}\right. \\
& \left.+\frac{C_{2} S}{d^{2}}\left(1-\frac{\alpha T^{\beta}}{(\beta+1)}\right)\left(\frac{2 d^{\prime 2}}{d}-d^{\prime \prime}\right)\right] \ldots \ldots \ldots \ldots(15) \\
\frac{\partial^{2} N}{\partial T \partial s}= & \left(c+C_{3}\right) \frac{d^{\prime}}{2}+C_{2} d^{\prime}\left\{1-\frac{\alpha \beta T^{\beta}}{(\beta+2)}-\frac{\alpha^{2}(2 \beta+1) T^{2 \beta}}{2(\beta+1)^{2}}\right\}+\frac{\alpha \beta C_{2} S d^{\prime} T^{\beta-1}}{d^{2}(\beta+1)}
\end{aligned}
$$

$$
\frac{\partial^{2} N}{\partial T^{2}} \prec 0 \text { and } \frac{\partial^{2} N}{\partial s^{2}} \prec 0,
$$

and $\left(\frac{\partial^{2} N}{\partial T^{2}} \frac{\partial^{2} N}{\partial s^{2}}-\frac{\partial^{2} N}{\partial T \partial s}\right) \succ 0$,

Since $\mathrm{d}(\mathrm{s})=(\mathrm{a}-\mathrm{bs}), d^{\prime}=-b$ and $d^{\prime \prime}=0$ then the optimum

Values of $\mathrm{T}^{*}$ and $\mathrm{s}^{*}$ satisfy the equations (17) \& (18), and for the values of $\mathrm{T}^{*}$ and $\mathrm{s}^{*}$ net profit is given by the equation (11).

The optimal replenishment lot size is given by the equation

$$
\mathrm{Q}^{*}=\mathrm{D}\left(\mathrm{T}^{*}\right)+\mathrm{d}\left(\mathrm{s}^{*}\right) \mathrm{T}^{*}
$$

Now two cases arises

\section{Case1. Optimization of $\mathbf{T}$ when $\mathrm{s}$ as decision variable.}

Numerical example: $d(s)=20-(0.5) s$ unit/day, Item cost, $c=\$ 5.00 / d a y$, Set-up cost $C_{1}=\$ 10.00 /$ order, Holding cost $=C_{2}=0.50 /$ unit $/$ day in stock. Shortage cost, $C_{3}=\$ 2.00 /$ unit / day, back-ordered, $S=\$ 10.00 /$ unit , $\alpha=0.10,0.15,0.5,1.0,5.0, \beta=1$ if $s=\$ 20 /$ unit, then $d=\$ 10 /$ unit 
Table 1

\begin{tabular}{|c|c|c|c|}
\hline$\alpha$ & $\mathrm{T}$ & $\mathrm{Q} / \mathrm{T}$ & $\mathrm{NP}$ \\
\hline 0.10 & 41.9828 & 0.476385 & $1168.19399^{*}$ \\
\hline 0.15 & 27.96180 & 0.715262 & 812.38980 \\
\hline 0.50 & 8.39333 & 2.38284 & 312.25096 \\
\hline 1.00 & 4.21366 & 4.74647 & 204.06565 \\
\hline 5.00 & 0.94676 & 21.1247 & -22.93850 \\
\hline
\end{tabular}

Case2. Optimization of $\mathrm{s}$ when $\mathrm{T}$ as decision variable.

Numerical example: Let $d(s)=20-(0.5) s$ unit/day, Item cost, $c=\$ 5.00 /$ day, Set-up cost $C_{1}=\$ 10.00 /$ order, Holding cost $=C_{2}=0.50 /$ unit $/$ day in stock. Shortage cost, $C_{3}=\$ 2.00 /$ unit / day, back-ordered, $S=\$ 10.00 /$ unit $, \alpha=0.10,0.15,0.5,1.0,5.0, \beta=1$, $T=3$ days $\quad d^{\prime}=-(0.50)$

Table 2

\begin{tabular}{|c|c|c|}
\hline$\alpha$ & $\mathrm{s}$ & $\mathrm{NP}$ \\
\hline 0.10 & 16.5614 & $219.35088^{*}$ \\
\hline & 39.3900 & -25.3243 \\
\hline & 40.5945 & -193.37955 \\
\hline 0.15 & 14.0786 & 154.65238 \\
\hline & 39.7037 & -20.28050 \\
\hline 0.50 & 40.2930 & -85.6901 \\
\hline & 16.90310 & 213.616138 \\
\hline 1.00 & 39.6687 & -38.1886 \\
\hline 5.00 & 40.3267 & -57.044965 \\
\hline & 17.7087 & 191.670648 \\
\hline & 35.7942 & 109.62995 \\
\hline
\end{tabular}

Star (*) indicates optimal solution, Negative sign (-) indicates infeasible solution

\section{Conclusion}

In the present model when there is no shortage it is observed that the net profit increases when the deterioration parameter decreases and the selling price varies slightly. In the real market selling price of an item is the main factor for its demand and it optimizes the net profit. The other important factor for net profit is the replenishment time interval and the retailer's lot size is affected by the demand of the product and the demand of the product is dependent on the selling price of the product. Therefore in order to optimize the net profit either we increase the price of the product or decrease the replenishment cycle time. Hence this model becomes more practicable and very useful in the business organizations dealing with domestic goods, perishable products and other products.

\section{References}

[1]. R.P.Covert and G.C. Philip, American institute of Industrial Engineering transaction 5,323(1973).

[2]. G.C. Philip, AIIE transaction 6, 159(1974).

[3]. R.B. Misra, international journal of production research 13, 495(1975).

[4]. Y.K. Shah and M.C. Jaiswal, Opsearch 14,174(1977).

[5]. S.P. Aggarwal, Opsearch 15,184(1978).

[6]. M. Roy Choudhary and K. S. Chaudhary, Opsearch 20, 99 (1983).

[7]. P. Ghare and G. Schrader, journal of Industrial Engineering 14, 238 (1963).

[8]. P.R. Tadikamalla, AIIE Transaction 10, 108(1978).

[9]. S. Mukhopadhyay, R. N. Mukherjee, and K. S Chaudhuri, Computers and Industrial Engineering 47,339(2004).

[10]. S. Mukhopadhyay, R. N. Mukherjee, and K. S. Chaudhuri, International Journal of Mathematical Education in science and Technology 36,25(2005)

[11]. T. Chakrabarty, B. C. Giri, and K.S. Chaudhuri , Computer and Operation Research 25,649(1998)

[12]. S. K Goyal and B.C. Giri, European Journal of Operation Research 134,1(2001).

[13]. J. M. Chen and S. C. Lin, Journal of Information and Optimization Sciences 24,1(2003).

[14]. S. K. Ghosh and K. S. Chaudhuri, Advanced Modelling and Optimization 6,21(2004).

[15]. N.K.Mahapatra and M. Maiti, Computers and Mathematics with Applications 49, 805(2005).

[16]. B.Mandal ,A.K. Bhunia, and M. Maiti, Computers and Industrial Engineering 45, 443(2003).

[17]. J. W. Wu and W.C. Lee, Information and Optimization Science 24,10 3(2003).

[18]. H.M. Wagner and T. M. Whitin, Management Science 5, 89 (1958).

[19]. Y. Shah, AIIE Transactions 9, 190 (1977). 
[20]. V.P. Goel and S.P. Aggarwal, Proceedings of all India seminar on OR and Decision Making, University of Delhi, New Delhi, 19 (1981).

[21]. J.S. Kim, H. Hwang, and S. W. Shinn, Production Planning and control 6, 45 (1995)

[22]. H.M. Wee, International Journal of Production Economics 40,163 (1995).

[23]. P.L. Abad, Management Science 42,1093 (1996).

[24]. S. Ladary and A. Sterinleib, AIIE Transactions 6,35(1974).

[25]. S.K. Goyal and A. Gunasekaran, Computers and Industrial Engineering 28,41 (1977).

[26]. W. Luo, Computers and Industrial Engineering, 34, 685(1998)

[27]. K. Z.Weng, European Journal of Operation Research,86, 300 (1995).

[28]. S. Subramanyam and S. Kumaraswamy, AIIE Transactions 13, 312(1981).

[29]. K. Das, A. K. Bhunia and M. Maiti, IAPQR Transactions 24, 65(1999).

[30]. S.P. Aggarwal and C.K.Jaggi, International Journal of System Science 20,151(1989).

[31]. R. Begum, R.R. Sahoo, S.K.Sahu and M. Mishra, Journal of Scientific Research, 2(1), 24-36(2010). 